\title{
Electrically-Active Convection in Tropical Easterly Waves and Implications for Tropical Cyclogenesis in the Atlantic and East Pacific
}

\author{
K. Leppert II, Dept. Atmospheric Science, University of Alabama in Huntsville \\ W. Petersen, NASA GSFC/WFF (walt.petersen@nasa.gov) \\ D. Cecil, Earth Systems Sciences Center, University of Alabama in Huntsville
}

One possible key to improving tropical cyclone initiation forecasting is to understand how a given tropical wave disturbances acts to organize areas of deep convection and precipitation that form the "seeds" of incipient tropical storms and/or hurricanes. Because on average only one in ten tropical waves tend to develop tropical cyclones, it is beneficial to be able to recognize clues that suggest eventual intensification of any given wave. Related questions would be: Can satellite remote sensing tools be used to identify incipient cyclone "seeds" of intensification within a given tropical wave? More specifically, can the observed strength and evolution of deep convective storms and precipitation typically observed in tropical disturbances be used as a metric for indications of future tropical cyclone development?

To answer the aforementioned questions, in this study we investigate the evolution of individual convective storm structures within tropical easterly waves across the Atlantic and Eastern Pacific Ocean Basins. We examine diagnostics of convective storm intensity (infrared cloud top temperatures, lightning, and microwave brightness temperatures) as a function of the surrounding environment (e.g., large scale mass and moisture convergence profiles in the disturbances) as a means to assess the mechanisms by which convective storms might influence cyclone development and the potential role/use of convective storm intensity observations for predicting tropical cyclogenesis. We use data from the Tropical Rainfall Measurement Mission (TRMM) satellite Microwave Imager (TMI), Precipitation Radar (PR), and Lightning Imaging Sensor (LIS) as well as infrared (IR) brightness temperature data from the NASA global-merged IR brightness temperature dataset to evaluate convective storm intensities within given easterly waves across the Atlantic and Pacific regions of study and how those intensity diagnostics differ between tropical easterly waves that do or do not spawn tropical cyclones

The study results suggest that convective storm intensity diagnostics that best distinguish developing from non-developing cyclone waves vary as a function of where a given wave actually spawns a tropical cyclone. For waves that develop cyclones in the Atlantic basin, coverage by IR brightness temperatures less than $240 \mathrm{~K}$ and $210 \mathrm{~K}$ seems to provide the best distinction between developing and non-developing waves. Over the East Pacific several variables seem to provide a significant distinction between cyclone-developing and nondeveloping waves. These variables include the same IR temperature coverage thresholds as observed in the Atlantic Basin, in addition to lightning flash rate, and low-level $(<4.5 \mathrm{~km})$ PR reflectivity which are all increased in the convection of easterly waves that develop cyclones. The results of this study are consistent with previously hypothesized feedbacks between wave convective structures and tropical cyclogenesis, and also reasonably suggest that satellite remote sensing diagnostics that discern the intensity of storm clusters within tropical disturbances may provide some guidance for distinguishing waves that are or are not likely to develop tropical cyclones. 


\section{Monthly Weather Review}

\section{Electrically-Active Convection in Tropical Easterly Waves and Implications for Tropical Cyclogenesis in the Atlantic and East Pacific

\author{
--Manuscript Draft--
}

\begin{tabular}{|c|c|}
\hline \multicolumn{2}{|l|}{ Manuscript Number: } \\
\hline Corresponding Author: & $\begin{array}{l}\text { Kenneth David Leppert II } \\
\text { University of Alabama in Huntsville } \\
\text { Huntsville, AL UNITED STATES }\end{array}$ \\
\hline Corresponding Author's Institution: & University of Alabama in Huntsville \\
\hline First Author: & Kenneth David Leppert II \\
\hline \multirow[t]{2}{*}{ Order of Authors: } & Kenneth David Leppert II \\
\hline & Walter Petersen \\
\hline & \\
\hline
\end{tabular}


3 Electrically-Active Convection in Tropical Easterly Waves and Implications for Tropical Cyclogenesis in the Atlantic and East Pacific

21 *Corresponding author address: Kenneth Leppert II, NSSTC, 320 Sparkman Dr Rm 4074, Huntsville, AL

$22 \quad 35805$

23 E-mail: leppert@nsstc.uah.edu 
ABSTRACT

In this study, we investigate the characteristics of tropical easterly wave convection and

26 the possible implications of convective structure on tropical cyclogenesis and intensification over

27 the Atlantic Ocean and East Pacific using data from the Tropical Rainfall Measurement Mission

28 Microwave Imager, Precipitation Radar (PR), and Lightning Imaging Sensor as well as infrared

29 (IR) brightness temperature data from the NASA global-merged IR brightness temperature

30 dataset.

Easterly waves were partitioned into northerly, southerly, trough, and ridge phases based

32 on the 700-hPa meridional wind from the NCEP-NCAR reanalysis dataset. Waves were

33 subsequently divided according to whether they did or did not develop tropical cyclones (i.e.,

34 developing and nondeveloping, respectively), and developing waves were further subdivided

35 according to development location. Finally, composites as a function of wave phase and

36 category were created using the various datasets.

37 Results suggest that the convective characteristics that best distinguish developing from

38 nondeveloping waves vary according to where developing waves spawn tropical cyclones. For

39 waves that developed a cyclone in the Atlantic basin, coverage by IR brightness temperatures

$40 \leq 240 \mathrm{~K}$ and $\leq 210 \mathrm{~K}$ provide the best distinction between developing and nondeveloping waves.

41 In contrast, several variables provide a significant distinction between nondeveloping waves and

42 waves that develop cyclones over the East Pacific as these waves near their genesis location

43 including IR threshold coverage, lightning flash rates, and low-level $(<4.5 \mathrm{~km})$ PR reflectivity.

44 Results of this study may be used to help develop thresholds to better distinguish developing

45 from nondeveloping waves and serve as another aid for tropical cyclogenesis forecasting. 


\section{Introduction}

African easterly waves (AEWs) form in the tropical easterlies over east-central Africa (e.g., Burpee 1972; Norquist et al. 1977; Reed et al. 1977; Berry and Thorncroft 2005;

Thorncroft et al. 2008) and often form the necessary precursor low-level disturbance for tropical cyclogenesis (Kurihara and Tuleya 1981). These waves are important for tropical cyclogenesis not only in the Atlantic (e.g., Landsea 1993), but also in the East Pacific (e.g., Avila 1991; Avila and Pasch 1992; Molinari and Vollaro 2000; note, however, that not all easterly waves found over the East Pacific originate over Africa; e.g., Serra et al. 2008, 2010).

One outstanding question is why some waves develop tropical cyclones while others do not. Many factors that play a role in determining whether a wave develops involve the environment through which an easterly wave propagates. For example, a wave may be more likely to develop a tropical cyclone if it propagates through a region of weak vertical wind shear, SSTs $>27^{\circ} \mathrm{C}$, below-average sea-level pressure, above-normal low-level relative vorticity, and/or above-average precipitable water (all conditions favorable for tropical cyclogenesis; e.g., Gray 1968; Landsea et al. 1998; Bracken and Bosart 2000).

Hopsch et al. (2010) suggest that the structure of AEWs near the West African coast may be another important influence for determining the likelihood of cyclone development. In that study, developing waves were associated with higher values of relative humidity as well as stronger mid- and low-level circulations compared to nondeveloping waves (NDWs). In addition, it was found that developing waves tend to undergo a transformation from a cold-core structure over the African continent to a warm-core structure at the coast and over the ocean, consistent with cyclogenesis, while NDWs showed no such transformation. Results of Hopsch et 
71 al. (2010) also indicated that differences in the structure of developing waves and NDWs at the

72 coast could influence the likelihood of development out to $60^{\circ} \mathrm{W}$ over the Atlantic Ocean.

Easterly waves are often associated with convection at some point in their lifetime (e.g.,

74 Burpee 1974; Thompson et al. 1979; Duvel 1990; Petersen et al. 2003; Petersen and Boccippio

75 2004; Leppert and Petersen 2010; hereafter LP10), and differences in the nature of this

76 convection between different waves may be another determinant for why some waves develop

77 while others do not. Via thermodynamic and dynamic feedbacks between the smaller convective

78 scale and larger synoptic scale, more intense and/or widespread convection associated with

79 developing waves could help to produce conditions in the wave more favorable for development.

80 One possible effect of convection on the larger scale favorable for tropical cyclogenesis

81 is an increase in mid- to low-level vorticity. Ritchie and Holland (1997) showed how many

82 midlevel, convective-scale vortices created by convection can interact and merge, resulting in

83 one larger, cyclonic circulation (i.e., mesoscale convective vortex), helping to increase midlevel

84 vorticity on a larger scale. Hendricks et al. (2004) and Montgomery et al. (2006) used numerical

85 model simulations to describe a similar process near the surface whereby convection can help to

86 increase low-level vorticity and aid cyclogenesis. In particular, intense convective towers (i.e.,

87 vortical hot towers) were found to acquire large values of vertical vorticity via the tilting and

88 stretching of preexisting vorticity by convective updrafts. Montgomery et al. (2006) suggest that

89 a population of many growing, merging, and decaying towers acts as a quasi-steady diabatic

90 heating rate which feeds back to the large-scale circulation. In order for the circulation to remain

91 in thermal wind balance a secondary radial circulation develops with inflow near the surface.

92 This near-surface inflow encourages vortex merger, the concentration of low-level vorticity, and

93 the intensification of the cyclone (Hendricks et al. 2004; Montgomery et al. 2006). Several 
94 observation-based studies have also provided evidence for the importance of hot towers for

95 increasing low-level vorticity and aiding tropical cyclogenesis (e.g., Reasor et al. 2005; Sippel et

96 al. 2006; Houze et al. 2009).

97 Another potential contribution of persistent, widespread convection to the genesis process

98 is the moistening of mid and upper levels via transport of moisture from the surface. In

99 particular, Dunkerton et al. (2009) emphasizes the importance for tropical cyclogenesis of the

100 containment and accumulation of moisture transported by convection within a Lagrangian re-

101 circulation region of the trough phase of an easterly wave. This moisture transport and/or

102 accumulation inhibits the development of evaporatively-cooled downdrafts and associated

103 transport of low equivalent potential temperatures to the surface, which is thought to inhibit

104 tropical cyclogenesis (Rotunno and Emanuel 1987). Nolan (2007) also showed the importance

105 of mid- and upper-level moistening for tropical cyclogenesis.

106 Because enhanced convection could potentially enhance the development of an easterly

107 wave circulation and structure more favorable for tropical cyclogenesis, it is not surprising that

108 previous studies have found developing waves to be associated with more intense and/or

109 widespread convection compared to NDWs. For example, Hopsch et al. (2010) used IR

110 brightness temperatures to determine that developing waves are, in fact, associated with more

111 widespread/intense convection. Chronis et al. (2007) used lightning frequency to infer the

112 intensity of convection and found that tropical cyclogenesis in the East Atlantic may be related to

113 enhanced electrical activity (i.e., more intense convection) over that region. In this case,

114 lightning represents a proxy for deep convective updrafts and robust mixed-phase microphysical

115 processes, previously demonstrated to be a prerequisite for the development of strong in-cloud

116 electric fields and associated lightning (e.g., Takahashi 1978; Rutledge et al. 1992; Williams et 
117 al. 1992; Zipser 1994; Saunders and Peck 1998; Deierling and Petersen 2008). In addition, Price

118 et al. (2007) showed that enhanced lightning over East Africa may also be associated with

119 cyclogenesis over the East Atlantic. Leary and Ritchie (2009) examined cloud clusters instead of

120 waves in the East Pacific and found that developing cloud clusters were associated with

121 significantly more lightning than nondeveloping clusters. LP10 examined IR brightness

122 temperatures as well as lightning associated with AEWs over several longitude bands stretching

123 from East Africa $\left(30^{\circ} \mathrm{E}\right)$ to the central Atlantic $\left(50^{\circ} \mathrm{W}\right)$. They found that over each longitude

124 band developing waves were associated with a greater coverage of more intense, electrically-

125 active convection compared to NDWs.

126 This study expands on previous studies by not only examining lightning and/or IR

127 brightness temperatures for clues about convection related to tropical cyclogenesis but also

128 examining microwave brightness temperatures from the Tropical Rainfall Measurement Mission

129 (TRMM) Microwave Imager (TMI) and radar reflectivity data from the TRMM Precipitation

130 Radar (PR). In particular, the purpose of this study is twofold: 1.) Determine which

131 observations/characteristics of convection provide the best distinction between developing waves

132 and NDWs. 2.) Determine whether the characteristics that provide the best distinction vary for

133 waves that develop tropical cyclones over different regions. This paper composites all easterly

134 wave observations over fixed regions (i.e., Eulerian framework), while a companion study

135 (Leppert and Cecil 2012) examines composites in a wave-following, Lagrangian sense. The

136 Eulerian methodology and the associated results from this paper could potentially be used to help

137 distinguish developing waves from NDWs for forecasting applications. In contrast, the

138 Lagrangian methodology used in Leppert and Cecil (2012) requires a priori information

139 describing when and where a wave developed a tropical cyclone, limiting its direct application to 
140 the forecasting process. But, the Lagrangian framework can provide information on the

141 evolution of waves in the days leading up to cyclogenesis (i.e., a greater understanding of the

142 genesis process) that cannot be obtained from the Eulerian approach.

\section{Data/Methodology}

reanalysis (Kalnay et al. 1996) 700-hPa meridional wind data (note that the reanalysis has a spatial [temporal] resolution of $2.5^{\circ}$ [six hours; averaged to one day for this study]).

151 Specifically, the various wave phases were identified by first calculating a daily average 152 meridional wind value between $5^{\circ}-20^{\circ} \mathrm{N}$ and then calculating a meridional wind anomaly

153 (relative to the mean at each longitude) for each day and longitude. Next, a 3-7 day bandpass 154 filter was applied to the anomalies in order to isolate the period of the easterly waves. The 155 filtered anomalies were subsequently normalized by the standard deviation valid at each

156 longitude, and the \pm 0.75 standard deviation threshold was used to identify the individual wave

157 phases. In particular, normalized anomalies greater (less) than $0.75(-0.75)$ were classified as the 158 southerly (northerly) phase. For a given day, values between northerly (southerly) and southerly 159 (northerly) phases were identified as trough (ridge) phases. Finally, to classify many of those 160 data points unable to be classified using meridional wind data alone, 700-hPa vorticity was 161 calculated using reanalysis zonal and meridional wind components and processed exactly as the 162 meridional wind data.

163 The analysis domain over which the wave phases were identified for this study was larger 164 than that used in LP10 and stretched from $130^{\circ} \mathrm{W}$ to $20^{\circ} \mathrm{E}$ and from $5^{\circ} \mathrm{N}$ to $20^{\circ} \mathrm{N}$, outlined in Fig. 
165 1. To examine the evolution of convection and cold cloudiness associated with the waves as 166 they propagated through our analysis domain, the full analysis domain was divided into five

167 longitude bands, also shown in Fig. 1. These bands stretched from $130^{\circ} \mathrm{W}$ to $95^{\circ} \mathrm{W}$ over the East 168 Pacific (EPC), from $95^{\circ} \mathrm{W}$ to $70^{\circ} \mathrm{W}$ over the Western Caribbean and far eastern Pacific region 169 (CAR; this band includes the Central American land mass as well as the northern part of South 170 America), from $70^{\circ} \mathrm{W}$ to $40^{\circ} \mathrm{W}$ over the West Atlantic (WAT), from $40^{\circ} \mathrm{W}$ to $15^{\circ} \mathrm{W}$ over the 171 East Atlantic (EAT; the eastern boundary of this band lies approximately along the West African 172 coast), and from $15^{\circ} \mathrm{W}$ to $20^{\circ} \mathrm{E}$ over Africa (AFR). The waves were analyzed for the months of 173 June-November for the 10-year span of 2001-2010. These are the months in which easterly 174 waves are the most pronounced (e.g., Carlson 1969; Gu et al. 2004) and when tropical cyclones 175 often develop in the Atlantic and East Pacific regions (National Hurricane Center [NHC] storm 176 reports; NHC 2011).

177 After the various wave phases were identified, the wave troughs were divided into 178 developing (i.e., waves that developed tropical cyclones that attained at least tropical storm 179 strength) and NDWs (i.e., waves that never developed a tropical cyclone; see Table 1 for 180 acronyms and definitions of each wave category used in this study) via information provided by 181 NHC (2011). In addition, developing waves were divided based on the longitude band over 182 which they developed a tropical depression. Once the trough phases were partitioned into 183 various categories, any of the other three wave phases found within three data points $\left(7.5^{\circ}\right)$ east 184 or west of each wave trough were considered to be part of that wave and used in the composites. 185 The Lightning Imaging Sensor (LIS) on board TRMM consists of an optical imager 186 capable of recording brief radiance events associated with lightning (Christian et al. 1992;

187 Boccippio et al. 2002) with an estimated detection efficiency of 70\%-90\% (Christian 1999; 
188 Boccippio et al. 2000, 2002; no correction for detection efficiency was utilized for this study). In

189 particular, we used the $0.5^{\circ}$ LIS flash counts and view time data to compute the daily lightning

190 flash density for $2.5^{\circ}$ grid boxes (total flash count divided by view time over the area of a $2.5^{\circ}$

191 grid box).

192 The PR is a phased array radar system operating at $13.8 \mathrm{GHz}$ (Kummerow et al. 1998;

193 Kozu et al. 2001). Specifically, attenuation-corrected radar reflectivity (Iguchi et al. 2000;

194 Meneghini et al. 2000; Iguchi et al. 2009) and a convective/stratiform classification (Awaka et al.

195 1998, 2009) from the PR 2A25 V6.0 product were utilized for this study. The reflectivity values

196 classified as convective were used to calculate mean convective reflectivity profiles for each $2.5^{\circ}$

197 box with 1-km height resolution from 1-18 km above ground level. Only convective rays of

198 data with a rain bottom below $2 \mathrm{~km}$ and not classified as warm rain were used in the construction

199 of these mean profiles to isolate the type of convection presumably most relevant for tropical

200 cyclogenesis.

201 The convective rain classification from 2A25 V6.0 was also used to tabulate the

202 percentage convective coverage over each $2.5^{\circ}$ box. Another coverage parameter was calculated

203 using data from the 4-km NASA global-merged IR brightness temperature dataset (Liu et al.

204 2009). Specifically, the fractional coverage by IR brightness temperatures $\leq 210 \mathrm{~K}$ and $\leq 240 \mathrm{~K}$

205 over each $2.5^{\circ}$ box was calculated to examine the coverage by cold cloudiness.

206 The TMI instrument is a nine-channel passive microwave radiometer (Kummerow et al.

207 1998). Four TMI channels were used in this study, including the $37.0 \mathrm{GHz}$ and $85.5 \mathrm{GHz}$

208 horizontally- and vertically-polarized channels. The measured radiances in these channels are

209 especially sensitive to scattering by ice (e.g., Spencer et al. 1989; Smith et al. 1992; Cecil and

210 Zipser 1999; Toracinta et al. 2002). Significant scattering and an accompanying reduction in the 
211 measured brightness temperatures at $85.5 \mathrm{GHz}$ can be accomplished by relatively small ice

212 particles $\left(\sim 10^{-4} \mathrm{~m}\right.$ in diameter $)$, but significant reductions in brightness temperatures at $37.0 \mathrm{GHz}$

213 require the presence of larger (millimeter-sized) particles (Toracinta et al. 2002). Therefore, a

214 significant reduction in 37.0-GHz brightness temperatures likely indicates a stronger updraft and

215 more intense convection required for the formation and maintenance of large ice particles in the

216 upper portions of clouds. The $85.5-\mathrm{GHz}$ channel has also been used in several earlier studies to

217 characterize the intensity and spatial extent of convection (e.g., Mohr and Zipser 1996; Cecil and

218 Zipser 1999; Mohr et al. 1999).

219 At 37.0 and $85.5 \mathrm{GHz}$, variations in surface emissivity and temperature can lead to large

220 variations in brightness temperature unrelated to the overlying atmosphere. To remove these

221 variations, we combined temperatures measured from both $85.5-\mathrm{GHz}$ channels into $85.5-\mathrm{GHz}$

222 polarization corrected temperatures $\left(\mathrm{PCT}_{85}\right)$ as defined by Spencer et al. (1989). Similarly, the

223 two 37.0-GHz channels were combined to form PCT $_{37}$ as defined by Toracinta et al. (2002) and

224 Cecil et al. (2002). Cecil and Zipser (2002) found that vigorous convection was generally

225 present when $\mathrm{PCT}_{85}$ were below $\sim 200 \mathrm{~K}$ and $\mathrm{PCT}_{37}$ were below $\sim 263 \mathrm{~K}$. Hence, only TMI

226 pixels with $\mathrm{PCT}_{85} \leq 200 \mathrm{~K}$ and $\mathrm{PCT}_{37} \leq 260 \mathrm{~K}$ were used to calculate an average $\mathrm{PCT}_{85}$ and

$227 \mathrm{PCT}_{37}$ over each $2.5^{\circ}$ box.

228 Lightning flash rates, mean convective reflectivity profiles, mean PCTs, percentage

229 convective coverage values, and IR fractional coverage values were subsequently composited as

230 a function of wave phase for the different wave types over the various longitude bands (Fig. 1).

231 Note that some developing wave composites were not created over every longitude band because

232 after initial tropical cyclone development, developing waves were no longer tracked. For

233 example, composites were created for waves which spawn tropical cyclones over the East 
234 Atlantic (i.e., East Atlantic developing waves; EADWs) over only the Africa and East Atlantic

235 longitude bands. EADWs were tracked up until they developed cyclones over the East Atlantic

236 but not farther west.

237 The parameters we analyze here basically relate to either the areal coverage of convection

238 (percentage convective coverage, coverage below IR brightness temperature thresholds) or the

239 vigor of convection that does occur (lightning flash rate, mean PCTs for pixels below certain

240 thresholds, mean convective reflectivity). The IR thresholds ( $210 \mathrm{~K}$ and $240 \mathrm{~K}$ ) go beyond

241 characterizing the convective area as cold anvils expand. Flash rate is somewhat related to both

242 the coverage and intensity of convection, but one or more elements of intense convection can

243 dominate this parameter much more than a large number of weak convective cells would. The

244 PCT thresholds used here restrict the analysis to only pixels related to strong, deep convection.

245 Hence, our mean PCT values are indicative of how strong that convection is when it does occur.

246 (Note that taking the mean PCT without using thresholds [not shown] would be more related to

247 the rain area and would be quite different than the mean PCTs with thresholds.) Similarly, our

248 mean reflectivity values consider only the pixels that are already classified as convective, so they

249 relate to how strong that convection is.

250 In order to test whether values from developing waves and NDWs are significantly

251 different, the analysis of variance statistical technique was used. This provides an estimate of the

252 error variance associated with some group of data and an estimate of the systematic variance

253 between groups of data. If the systematic variance is greater than the error variance, then the $\mathrm{f}$ -

254 statistic is used to test whether the systematic effect is significantly greater than the random error

255 effect. A significantly greater systematic effect suggests a high probability that differences

256 between groups of data are, indeed, real and not just due to chance. Note for this study that a 
257 difference is considered to be significant if the f-statistic indicates significance at or above the

$25899 \%$ level. Additional information on the analysis of variance technique can be found in

259 Panofsky and Brier (1958).

260

261

262

263

264

265

266

267

268

269

270

271

272

273

274

275

276

277

278

279

280

281

282

283

\section{Results}

\section{a. Comparison between East Atlantic Developing Waves and NDWs}

Table 2 shows the number of distinct easterly waves and the number of individual data points included in the trough phase composites of various wave categories, including EADWs and NDWs. Note that as a result of wave merger/splitting as well as the ambiguities associated with counting weak NDWs that alternately can be tracked for a short time over the analysis domain and then become too weak to be tracked, the number of distinct NDWs in Table 2 is only an estimate.

The composite coverage by IR brightness temperature thresholds are provided in Table 3 over various longitude bands for various wave categories, including for EADWs and NDWs. Over Africa, the coverage by temperatures $\leq 210 \mathrm{~K}$ and $\leq 240 \mathrm{~K}$ is significantly greater in all EADW phases (except for the $210 \mathrm{~K}$ threshold in the trough phase) compared to the corresponding NDW values. Over the East Atlantic, significantly greater EADW values are confined to only the trough and northerly phases. Similarly, the composite percentage convective coverage values for EADWs and NDWs in Table 4 indicate that coverage is greater for EADWs over both Africa and the East Atlantic in each wave phase, except the ridge phase over the East Atlantic. The differences between EADWs and NDWs in the northerly phase over both Africa and the East Atlantic are significant, and the difference between trough phase values over the East Atlantic is also relatively large (while not significant at the $99 \%$ level, it is 
284 significant at the 95\% level). Thus, as EADWs approach their genesis region over the East

285 Atlantic, the maximum convective and cold cloudiness coverage occurs ahead of and within the

286 wave trough where it may interact with the larger-scale wave helping to amplify the wave,

287 perhaps making it more favorable for cyclogenesis (LP10).

While the differences in composite lightning flash rates (Table 5) between EADWs and

289 NDWs over Africa are not significant at the 99\% level, all EADW phases, except the trough, are 290 associated with significantly higher flash rates than the corresponding NDW phases valid at the $29195 \%$ level. The trough value is similar for EADWs and NDWs over Africa. Consistent with 292 several previous studies which show a decrease in lightning over the ocean compared to land 293 (e.g., Christian et al. 2003), lightning decreases substantially over the East Atlantic compared to 294 Africa. Nevertheless, except in the southerly phase, all EADW flash rates over the East Atlantic 295 are greater than those of NDWs. But, these differences are relatively small (i.e., not significant 296 at the $99 \%$ level). Thus, the lightning data suggest that EADWs are generally associated with 297 more vigorous convection than that of NDWs.

298 Table 6 shows $\mathrm{PCT}_{37}$ and $\mathrm{PCT}_{85}$ values as a function of wave phase for various wave 299 types and regions. Differences between EADWs and NDWs over both Africa and the East 300 Atlantic are quite small and are not significant in any phase. Nevertheless, EADW values are 301 generally slightly less than those of NDWs over both regions, suggesting a slightly stronger ice 302 scattering signature and somewhat more vigorous convection for EADWs.

303 The difference between mean convective reflectivity values of EADWs and NDWs

304 (EADW minus NDW values) as a function of wave phase valid over the East Atlantic is shown 305 in Fig. 2. Note that differences are calculated and shown in Fig. 2 and all subsequent figures 306 only where the mean reflectivity values for both developing waves and NDWs are $\geq 18 \mathrm{dBZ}$ (the 
approximate minimum detectable signal of the PR; Yang et al. 2006). Differences are generally

308 positive in Fig. 2, indicating greater reflectivity values for EADWs. These larger reflectivity

309 values would presumably be associated with stronger updrafts and more vigorous convection in

310 order to support such reflectivity values. However, only the value at $2.5 \mathrm{~km}$ in the northerly

311 phase and 4.5-5.5 $\mathrm{km}$ in the southerly phase are significantly greater for EADWs (indicated by

312 squares in Fig. 2). Thus, considering how many levels and phases fail the significance tests, we

313 cannot infer much from the few levels that do show significance. In addition, the differences

314 between EADW and NDW reflectivity profiles over Africa (not shown) are also small and not

315 statistically significant.

316 In summary, EADWs appear to be associated with a greater coverage by convection and

317 cold cloudiness over both Africa and the East Atlantic compared to NDWs. There is only slight

318 indication of more intense convection associated with EADWs. These results are generally

319 consistent with the results of LP10 where developing waves were found to be associated with a

320 greater coverage by cold cloud tops and more lightning compared to NDWs. The coverage by

321 IR brightness temperatures $\leq 240 \mathrm{~K}$ and/or $\leq 210 \mathrm{~K}$ provide the greatest number of statistically

322 significant differences between EADWs and NDWs over both Africa and the East Atlantic, thus,

323 providing the best discrimination between EADWs and NDWs.

324 Some waves included in the NDW composite are associated with relatively little cold

325 cloudiness and convection and, from an operational forecasting perspective, would clearly be

326 distinguished from developing waves. Hence, a comparison between these NDWs and

327 developing waves is not particularly instructive. To make a comparison between developing

328 waves and NDWs associated with a similar probability of development, the archived Graphical

329 Tropical Weather Outlooks produced by the NHC were examined in order to identify easterly 
waves that were assigned a moderate (30-50\%) chance of genesis within 48 hours. Composites

331 were created for NDWs and all developing waves in 2009 and 2010 (the archived outlooks were

332 only available for the last two years of the study) at the times and locations when these waves

333 were assigned a 30-50\% chance of genesis by the NHC. Forty-two (117) distinct easterly waves

334 (individual trough data points) were included in these developing wave composites. Note that 40

335 of these 42 waves actually developed within 48 hours. Nine (42) distinct waves (trough points)

336 were included in the NDW composites. Table 7 shows the statistics for these $30-50 \%$ chance-

337 of-genesis developing and NDW composites valid over the full analysis domain (to maximize

338 the sample size). Coverage by IR brightness temperatures $\leq 240 \mathrm{~K}$, convective coverage, and

339 flash rates are greater in nearly all developing wave phases compared to the corresponding NDW

340 phases with the greatest differences generally found in the trough and northerly phases. In

341 addition, $\mathrm{PCT}_{37}$ values are smaller in all developing wave phases, except the southerly phase.

342 Therefore, when developing and NDWs were associated with an enhanced probability of

343 cyclogenesis according to the NHC, developing waves appear to be associated with more

344 widespread and intense convection, in general, in agreement with the results of the comparison

345 between all NDWs and EADWs. Note that none of the variables show statistically significant

346 differences between developing waves and NDWs associated with a moderate probability of

347 genesis, possibly due to relatively small sample sizes.

348 The climatological peak of tropical cyclone occurrence in the Atlantic occurs around

349 August-September (e.g., Landsea 1993). Hence, we wanted to examine possible intra-seasonal

350 impacts on our results by examining a comparison between EADWs and NDWs valid only for

351 August-September. In general, this comparison (not shown) revealed patterns similar to those

352 found for the comparison valid for June-November, especially over the East Atlantic (i.e., 
greater coverage and/or intensity of convection for EADWs). However, the magnitude of

354 differences between the two wave categories valid for the shortened time period were somewhat

355 smaller and less often statistically significant than observed for the comparison valid for the full

356 time period. Restricting the NDW composite to those waves that occur in August-September

357 may lead to a composite of waves that presumably propagate through an environment

358 climatologically more favorable for cyclogenesis (e.g., moister environment) and for more

359 widespread/intense convection compared to the full June-November sample.

\section{b. Comparison between West Atlantic - Caribbean Developing Waves and NDWs}

365 over either the West Atlantic or Caribbean were combined into a single category (i.e., West

366 Atlantic - Caribbean developing waves; WACDWs). The coverage by certain IR thresholds

367 shown in Table 3 indicate that WACDWs are associated with significantly greater coverage by

368 cold cloud tops compared to NDWs in all phases except the ridge over Africa, the West Atlantic,

369 and the Caribbean. WACDW ridge values over these regions are also greater than those of

370 NDWs, but not with 99\% level significance. Over the East Atlantic, only the coverage by cold

371 cloud tops in the trough phase is significantly greater for WACDWs. The coverage by cold

372 cloudiness in other WACDW phases over the East Atlantic is generally less than the

373 corresponding NDW values (the $240 \mathrm{~K}$ threshold in the southerly phase is actually significantly

374 less). Thus, a persistent large coverage by cold cloudiness in the trough phase may be important

375 for the genesis of tropical cyclones from WACDWs, while coverage by cold cloud tops in the

376 ridge phase is relatively unimportant for genesis. 
The percentage convective coverage values shown for WACDWs and NDWs in Table 4

378 indicate few significant differences between the two wave categories over any longitude band.

379 In fact, only the WACDW trough over the West Atlantic is associated with significantly more

380 convective coverage than the NDW trough. The coverage in the WACDW northerly phase over

381 the Caribbean is also much greater than the corresponding NDW value, but the difference is only

382 significant at the $95 \%$ level. Despite the relative lack of statistically significant differences,

383 convective coverage is greater in all WACDW phases over Africa, the West Atlantic, and the

384 Caribbean (except for the ridge over Africa and trough over the Caribbean). Over the East

385 Atlantic, coverage in the WACDW trough and ridge is greater than the corresponding NDW

386 values, while northerly and southerly values are nearly identical between the two wave

387 categories over this band. Thus, convective coverage is generally larger for WACDWs over all

388 longitude bands, especially as these waves approach their genesis region over either the West

389 Atlantic or Caribbean.

390 None of the WACDW lightning flash rates are significantly different from those of

391 NDWs (Table 5) over any longitude band. However, over Africa and the Caribbean, flash rates

392 for all WACDW phases are greater than the corresponding NDW values. Flash rates over the

393 East and West Atlantic are also generally slightly greater for WACDWs. The mean PCTs from

394 deep convection in WACDWs (Table 6) also suggest no significant differences between

395 WACDW and NDW values with some values slightly greater for WACDWs and others slightly

396 greater for NDWs. Hence, the intensity of convection associated with WACDWs as indicated by

397 lightning and low PCTs does not appear to be all that different from that of NDWs.

398 The differences between mean vertical profiles of convective reflectivity for WACDWs

399 and NDWs as a function of wave phase over various longitude bands are shown in Fig. 3. Very 
400 few of the differences between WACDWs and NDWs are significant. Only values at 3.5-4.5 km

401 in the northerly phase over the Caribbean and 3.5-5.5 km in the trough over the West Atlantic

402 are significantly greater for WACDWs. Despite the lack of significant differences, reflectivity

403 values are greater for WACDWs at all heights in all phases, except the ridge, as these waves

404 approach their genesis region over the Caribbean. In contrast, over Africa, NDWs are generally

405 associated with greater reflectivity values in all phases, except the northerly phase. Hence, as

406 WACDWs move from their origin over Africa to where they develop tropical cyclones over the

407 West Atlantic and Caribbean, convective reflectivity values associated with these waves

408 generally increase slightly relative to NDWs.

409 Similar to EADWs, the coverage by cold cloudiness (i.e., using IR thresholds) provides

410 the greatest number of statistically significant differences between WACDWs and NDWs and

411 appears to be the best discriminator between these two wave types, especially within the trough

412 phase. While convective coverage, lightning flash rates, mean cold PCTs, and convective

413 reflectivity provide few statistically significant differences between WACDWs and NDWs, these

414 variables appear to indicate that WACDWs are associated with a greater coverage and intensity

415 of convection as these waves approach their genesis region. This enhancement of convection

416 associated with WACDWs may help to moisten the larger-scale waves at mid/upper levels (e.g.,

417 Dunkerton et al. 2009) and/or increase larger-scale mid to low-level vorticity (e.g., Montgomery

418 et al. 2006; Nolan 2007; Raymond et al. 2011), helping to create an environment more favorable

419 for tropical cyclogenesis.

420 A comparison was also made between WACDWs and NDWs valid only for those months

421 when WACDWs are most active (i.e., August-October) as indicated by the annual distribution of 
422 WACDW data points (not shown). Similar to EADWs, the restricted WACDW comparison

423 generally did not change the results obtained from the full June-November comparison.

424

425

426

427

428

429

430

431

432

433

434

435

436

437

438

439

440

441

442

443

444

445

446

\section{c. Comparison between East Pacific Developing Waves and NDWs}

Waves that developed tropical cyclones over the East Pacific (i.e., East Pacific

developing waves; EPDWs) are obviously a long distance from where they develop tropical cyclones while the waves are near their origin over Africa, and there are several complicating factors (e.g., topography of Central America; Zehnder 1991; Mozer and Zehnder 1996; Farfan and Zehnder 1997; Zehnder et al. 1999; barotropic instability over the Caribbean and East Pacific; Molinari et al. 1997) that could influence an EPDW between Africa and the East Pacific. Hence, convection over Africa would not be expected to exert much of an influence on later tropical cyclogenesis over the East Pacific. Nevertheless, EPDW lightning flash rates and coverage by cold cloudiness valid for June-November (not shown) are significantly greater than corresponding NDW values in various wave phases over Africa. However, the June-November NDW composite over Africa includes all waves, including those waves that were too weak to track all the way across the Atlantic and waves with relatively little convection. A comparison between EPDW and NDW composites valid for only July and August (two of the most active months for tropical cyclogenesis in the East Pacific), which restricts the NDW composite to those waves that presumably move through an environment climatologically more favorable for convection and for cyclogenesis, shows a much different pattern than that observed for JuneNovember. For example, the coverage by IR brightness temperatures below certain thresholds over Africa valid for July-August only (Table 8) shows smaller EPDW coverage in all phases ( $240 \mathrm{~K}$ threshold differences are significant in every phase, except the ridge phase, while $210 \mathrm{~K}$ 
447 differences are significant in the trough and northerly phases) compared to the corresponding

448 NDW values. Thus, the focus of this subsection will be on a comparison between EPDWs and

449 NDWs valid for July-August because this restricted comparison appears to provide more

450 meaningful results than those obtained from the June-November comparison.

As EPDWs move over the East and West Atlantic, the coverage by cold cloudiness

452 (Table 8) becomes comparable to that of NDWs with some values greater for EPDWs and other 453 values greater for NDWs with no significant differences. Over the Caribbean and East Pacific,

454 all IR threshold coverage values are greater for EPDWs. Values are significantly greater in the 455 EPDW southerly phase over the Caribbean and all phases over the East Pacific (except for the $456210 \mathrm{~K}$ value in the ridge). Convective coverage (not shown) is generally greater for NDWs over 457 Africa, the East Atlantic, and West Atlantic, but differences between these waves and EPDWs 458 are generally not significant. In contrast, convective coverage is often greater for EPDWs over 459 the Caribbean and East Pacific with significantly greater values in the southerly phase over the 460 Caribbean and northerly and southerly phases over the East Pacific. Thus, relative to NDWs, 461 convective and cold cloudiness coverage is smaller for EPDWs over Africa and generally 462 increases as EPDWs move across the Atlantic and approach their genesis region.

463 Composite lightning flash rates for EPDWs and NDWs (Table 9) indicate that flash rates 464 are smaller in all EPDW phases over Africa compared to the corresponding NDW values, but 465 differences are not significant. Over the East Atlantic, West Atlantic, and Caribbean, flash rates 466 are comparable between EPDWs and NDWs with some values greater for EPDWs and others 467 greater for NDWs. When EPDWs are over the East Pacific where they develop tropical 468 cyclones, flash rates in all phases of these waves are greater (significantly greater in all but the 469 ridge phase) than the corresponding NDW values. 
A comparison between EPDW and NDW cold PCTs (not shown) indicates, similar to

471 other developing waves, little difference between the two wave types. However, over the East

472 Pacific, EPDW trough and southerly phase $\mathrm{PCT}_{85}$ values are significantly less than the

473 corresponding NDW values, suggesting more intense convection for these waves near their

474 genesis region. Overall, though, differences between developing waves (EADWs, WACDWs,

475 and EPDWs) and NDWs in terms of mean cold PCTs are quite small over all longitude bands,

476 suggesting that this way of comparing PCTs (taking the mean of pixels below a threshold for

477 deep convection) may not be the best use of passive microwave information.

478 Over all longitude bands east of the East Pacific band, differences between EPDWs and

479 NDWs in terms of mean convective reflectivity profiles (not shown) are generally small with few

480 statistically significant differences. Differences in convective reflectivity profiles between

481 EPDWs and NDWs over the East Pacific (Fig. 4) indicate generally greater values for EPDWs in

482 all phases at all levels. EPDW values are significantly greater between 2.5 and $5.5 \mathrm{~km}$ in the

483 northerly phase, at $2.5 \mathrm{~km}$ in the trough, and at $3.5 \mathrm{~km}$ in the southerly phase. Thus, when

484 EPDWs are near their origin over Africa, differences between these waves and NDWs in terms

485 of convective reflectivity are small. Differences remain small until EPDWs move over their

486 genesis region of the East Pacific, where low- to mid-level reflectivity values become

487 significantly greater for these waves in all phases other than the ridge.

488 In summary, EPDW convective coverage and/or intensity appear to be relatively low

489 compared to NDWs near their origin over Africa. As EPDWs move across the Atlantic,

490 Caribbean, and into the East Pacific region, convective coverage and/or intensity gradually

491 become significantly greater than that of NDWs. The pronounced increase in convection over

492 the Caribbean and East Pacific may be related to barotropic instability found over these regions 
493 (Molinari et al. 1997). It is possible that this instability over the Caribbean and East Pacific 494 could help amplify easterly waves, perhaps helping to spawn more convection within the waves 495 over these regions. In addition, the Caribbean region may be associated with an enhancement of 496 convection due to the large landmasses in that region (cf. Fig. 1). Note that both EPDWs and 497 NDWs are subject to the effects of land and its associated diurnal cycle of convection over the 498 Caribbean region. Thus, any differences observed between these two wave types in terms of 499 characteristics of convection should not be due to land/ocean differences. In contrast to EADWs and WACDWs where the coverage by IR thresholds was clearly 501 the one variable that could provide the best discrimination between these waves and NDWs, 502 several variables could potentially be used to separate EPDWs from NDWs over the East Pacific, 503 including IR thresholds, lightning flash rates, and low-level PR convective reflectivity values. 504 This may suggest that the coverage and intensity of convection over the East Pacific are 505 important for tropical cyclogenesis over this region.

506 Based on NHC (2011), some waves spawned a tropical cyclone in both the Atlantic and 507 East Pacific basins. To determine if there were any differences in terms of convective 508 characteristics between these waves which spawned multiple cyclones and those which spawned 509 only one storm, composites were created for waves that developed multiple cyclones. However, 510 few significant differences were found between multiple and single cyclone waves. Waves 511 which develop multiple cyclones may lend themselves better to case study analysis which is left 512 for future work.

513 Again using information from NHC (2011), developing waves were also separated 514 according to whether the subsequent tropical cyclone achieved hurricane strength or only tropical 515 storm strength. Composites were also created for both of these wave categories. Except for 
516 some differences between hurricane and tropical storm waves over the West Atlantic, the

517 convective characteristics of hurricane and tropical storm waves are generally not significantly

518 different. These results are not surprising because many other factors (e.g., SSTs, wind shear)

519 help control the final strength of a tropical cyclone. In addition, because we are not controlling

520 for large-scale conditions, the relative enhancement of convection in hurricane waves over the

521 West Atlantic could be a result of large-scale conditions favorable for both convection and

522 intensification to hurricane strength. In this case, the enhanced convection in the precursor wave

523 is not a factor responsible for intensification to hurricane strength.

524

\section{Summary and Conclusions}

529 tropical easterly waves using data from the Tropical Rainfall Measurement Mission (TRMM)

530 Lightning Imaging Sensor, Precipitation Radar (PR), and Microwave Imager as well as IR

531 brightness temperatures from the NASA global-merged dataset. In particular, the purpose of the

532 study was to determine which characteristics or observations of convection provide the best

533 distinction between developing waves and nondeveloping waves (NDWs) and over which

534 regions. Another goal of the study was to determine whether the convective characteristics that

535 provide the best distinction between the two wave types vary for waves that develop tropical

536 cyclones over different regions.

537 Results suggest that the variables that provide the best distinction between developing

538 waves and NDWs do vary between the Atlantic and East Pacific. In particular, the coverage by

539 IR brightness temperatures $\leq 240 \mathrm{~K}$ and $\leq 210 \mathrm{~K}$ appear to provide the largest distinction between

540 East Atlantic developing waves (EADWs; waves which developed a tropical cyclone over the 
541 East Atlantic) and NDWs in all wave phases over Africa and in the trough and northerly phases

542 over the East Atlantic. The coverage by IR thresholds also provides the best distinction between

543 West Atlantic - Caribbean developing waves (WACDWs; waves which spawned a cyclone over

544 either the West Atlantic or Caribbean) and NDWs. In particular, the coverage by cold cloudiness

545 was found to be significantly greater for WACDWs in all phases, except the ridge, over all

546 longitude bands but the East Atlantic (values are only significantly greater for WACDWs in the

547 trough over the East Atlantic). Thus, results for WACDWs indicate that a persistent large

548 coverage by cold cloudiness in the trough phase may be important for cyclogenesis from these

549 waves. The fact that indices of the coverage by convection/cold cloudiness provide a better

550 discrimination between developing waves over the Atlantic and NDWs than indicators of

551 convective intensity (e.g., lightning flash rates, polarization corrected temperatures) suggests that

552 the coverage by convection is more important than intensity for tropical cyclogenesis over the

553 Atlantic.

554 In contrast to waves which developed a tropical cyclone over the Atlantic basin, waves

555 which spawned a tropical cyclone over the East Pacific (East Pacific developing waves; EPDWs)

556 are associated with statistically significantly greater IR threshold coverage, convective coverage,

557 lightning flash rates, and low-level PR convective reflectivity in various wave phases (no clear

558 preference for enhanced convection in any one wave phase over another) when compared to

559 NDWs over the East Pacific. In contrast to what was found for EADWs and WACDWs,

560 restricting the comparison between EPDWs and NDWs to only the most active months for East

561 Pacific cyclogenesis led to quite different results from the corresponding comparison valid for

562 June-November, especially over Africa. This suggests that care must be taken in selecting a 
563 temporal domain for a comparison between EPDWs and NDWs and/or selecting a sample of 564 NDWs.

565 Future work could involve developing thresholds based on the most relevant convective

566 parameters to help provide an indication of enhanced probability (or lack thereof) of tropical

567 cyclogenesis. For example, Table 10 lists the most relevant parameters for EADWs, WACDWs,

568 and EPDWs over various regions and initial thresholds that could be tested for each parameter.

569 These thresholds are based approximately on the 99\% significance level for the sample sizes

570 used for this study. Other future work could involve incorporating these convective indicators

571 that provide the greatest distinction between developing waves and NDWs in the development of

572 a statistical cyclogenesis/hurricane prediction model.

573

574

575

576

577

578

579

580

581

582

583

584

585

586

587

\section{Acknowledgements.}

This work was part of the lead author's research for his doctoral degree, and funding for the research was provided through a NASA Earth and Space Science Fellowship, Grant \#NNX09AO40H. Dr. Walter Petersen and Dr. Daniel Cecil also acknowledge funding from the NASA PMM/TRMM Program. Suggestions from Dr. Ron McTaggart-Cowan and two anonymous reviewers greatly improved an earlier version of this manuscript. The authors would also like to gratefully acknowledge the Goddard Earth Sciences Data and Information Services Center for providing the TMI, PR, and IR brightness temperature data, the NASA EOSDIS Global Hydrology Resource Center DAAC for providing the LIS science data, and the NOAA/OAR/ESRL PSD for providing the NCEP-NCAR reanalysis data. 


\section{REFERENCES}

589 Avila, L. A., 1991: Eastern North Pacific hurricane season of 1990. Mon. Wea. Rev., 119, $2034-2046$. , and R. J. Pasch, 1992: Atlantic tropical systems of 1991. Mon. Wea. Rev., 120, $2688-2696$.

Awaka, J., T. Iguchi, and K. Okamoto, 1998: Early results on rain type classification by the Tropical Rainfall Measuring Mission (TRMM) precipitation radar. Proc. Eighth URSI Commission F. Triennial Open Symp., Aveiro, Portugal, International Union of Radio Science, 143-146. , and ,2009, TRMM PR standard algorithm 2A23 and its performance on bright band detection. J. Meteor. Soc. Japan, 87A, 31-52.

Berry, G. J., and C. Thorncroft, 2005: Case study of an intense African easterly wave. Mon. Wea. Rev., 133, 752-766.

Boccippio, D. J., S. J. Goodman, and S. Heckman, 2000: Regional differences in tropical lightning distributions. J. Appl. Meteor., 39, 2231-2248. , W. J. Koshak, and R. J. Blakeslee, 2002: Performance assessment of the optical transient detector and lightning imaging sensor. Part I: Predicted diurnal variability. $J$. Atmos. Oceanic Technol., 19, 1318-1332. cyclogenesis over the North Atlantic Ocean. Mon. Wea. Rev., 128, 353-376. North Africa. J. Atmos. Sci., 29, 77-89. 

, 1974: Characteristics of North African easterly waves during the summers of 1968 and 1969. J. Atmos. Sci., 31, 1556-1570.

612 Carlson, T. N., 1969: Synoptic histories of three African disturbances that developed into 613 Atlantic hurricanes. Mon. Wea. Rev., 97, 256-276.

614 Cecil, D. J., and E. J. Zipser, 1999: Relationships between tropical cyclone intensity and satellite-based indicators of inner core convection: $85-\mathrm{GHz}$ ice-scattering signature and lightning. Mon. Wea. Rev., 127, 103-123.

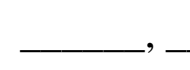
, and S. W. Nesbitt, 2002: Reflectivity, ice scattering, and lightning characteristics of hurricane eyewalls and rainbands. Part I: Quantitative description. Mon. Wea. Rev., 130, 769-784. , and , 2002: Reflectivity, ice scattering, and lightning characteristics of hurricane eyewalls and rainbands. Part II: Intercomparison of observations. Mon. Wea. Rev., 130, $785-801$.

Christian, H. J., R. J. Blakeslee, and S. L. Goodman, 1992: Lightning Imaging Sensor (LIS) for the Earth Observing System. NASA TM-4350, 36 pp. , 1999: Atmospheric Electricity, Guntersville, AL, NASA/CP-1999-209261, 715-718. , and Coauthors, 2003: Global frequency and distribution of lightning as observed from space by the optical transient detector. J. Geophys. Res., 108, 4005, doi:10.1029/2002JD002347.

Chronis, T. G., E. R. Williams, E. N. Anagnostou, and W. A. Petersen, 2007: African lightning: Indicator of tropical Atlantic cyclone formation. Eos, Trans. Amer. Geophys. Union, 88, $397-398$. 
632 Deierling, W., and W. A. Petersen, 2008: Total lightning activity as an indicator of updraft characteristics. J. Geophys. Res., 113, D16210, doi:10.1029/2007JD009598.

634 Dunkerton, T. J., M. T. Montgomery, and Z. Wang, 2009: Tropical cyclogenesis in a tropical wave critical layer: Easterly waves. Atmos. Chem. Phys., 9, 5587-5646.

Duvel, J-Ph., 1990: Convection over tropical Africa and the Atlantic Ocean during northern summer. Part II: Modulation by easterly waves. Mon. Wea. Rev., 118, 1855-1868.

Farfan, L. M., and J. A. Zehnder, 1997: Orographic influence on the synoptic-scale circulations

Gray, W. M., 1968: Global view of the origin of tropical disturbances and storms. Mon. Wea.

Gu, G., R. F. Adler, G. J. Huffman, and S. Curtis, 2004: African easterly waves and their Rev., 96, 669-700.

Hendricks, E. A., M. T. Montgomery, and C. A. Davis, 2004: The role of "vortical" hot towers in association with precipitation. J. Geophys. Res., 109, D04101, the formation of tropical cyclone Diana (1984). J. Atmos. Sci., 61, 1209-1232.

Hopsch, S. B., C. D. Thorncroft, and K. R. Tyle, 2010: Analysis of African easterly wave structures and their role in influencing tropical cyclogenesis. Mon. Wea. Rev., 138, 13991419.

Houze, R. A., Jr., W.-C. Lee, and M. M. Bell, 2009: Convective contribution to the genesis of Hurricane Ophelia (2005). Mon. Wea. Rev., 137, 2778-2800.

653 Iguchi, T., T. Kozu, R. Meneghini, J. Awaka, and K. Okamoto, 2000: Rain-profiling algorithm for the TRMM precipitation radar. J. Appl. Meteor., 39, 2038-2052. 

, J. Kwiatkowski, R. Meneghini, J. Awaka, and K. Okamoto, 2009: Uncertainties in the rain profiling algorithm for the TRMM precipitation radar. J. Meteor. Soc. Japan, 87A, 1-30.

658 Kalnay, E., and Coauthors, 1996: The NCEP/NCAR 40-year reanalysis project. Bull. Amer. Meteor. Soc., 77, 437-471.

660 Kozu, T., and Coauthors, 2001: Development of precipitation radar onboard the Tropical Rainfall Measuring Mission (TRMM) satellite. IEEE Trans. Geosci. Remote Sens., 39, $102-116$.

663 Kummerow, C., W. Barnes, T. Kozu, J. Shiue, and J. Simpson, 1998: The tropical rainfall measuring mission (TRMM) sensor package. J. Atmos. Oceanic Technol., 15, 809-817.

Landsea, C. W., 1993: A climatology of intense (or major) Atlantic hurricanes. Mon. Wea. Rev.,

Kurihara, Y., and R. E. Tuleya, 1981: A numerical simulation study on the genesis of a tropical 121, 1703-1713.

670 storm. Mon. Wea. Rev., 109, 1629-1653.

672 Leary, L. A., and E. A. Ritchie, 2009: Lightning flash rates as an indicator of tropical

673 cyclone genesis in the Eastern North Pacific. Mon. Wea. Rev., 137, 3456-3470.

674 Leppert, K. D., II, and W. A. Petersen, 2010: Electrically-active hot towers in African

675 easterly waves prior to tropical cyclogenesis. Mon. Wea. Rev., 138, 663-687. 
, and D. J. Cecil, 2012: African easterly wave convection and tropical cyclogenesis: A Lagrangian perspective. Extended Abstracts, $30^{\text {th }}$ Conf. on Hurricanes and Tropical Meteorology, Ponte Vedra Beach, FL, Amer. Meteor. Soc., 3C.6.

Liu, Z., D. Ostrenga, G. G. Leptoukh, and A. V. Mehta, 2009: Online visualization and analysis of global half-hourly pixel-resolution infrared dataset. Extended Abstracts, $25^{\text {th }}$ Conf. on International Interactive Information and Processing Systems (IIPS) for Meteorology, Oceanography, and Hydrology, Phoenix, AZ, Amer. Meteor. Soc., J3.4.

Meneghini, R., T. Iguchi, T. Kozu, L. Liao, K. Okamoto, J. A. Jones, and J. Kwiatkowski, 2000: Use of the surface reference technique for path attenuation estimates from the TRMM precipitation radar. J. Appl. Meteor., 39, 2053-2070.

Mohr, K. I., and E. J. Zipser, 1996: Defining mesoscale convective systems by their 85-GHz icescattering signatures. Bull. Amer. Meteor. Soc., 77, 1179-1189. , J. S. Famiglietti, and E. J. Zipser, 1999: The contribution to tropical rainfall with respect to convective system type, size, and intensity estimated from the $85-\mathrm{GHz}$ icescattering signature. J. Appl. Meteor., 38, 596-606.

Molinari, J., and D. Vollaro, 2000: Planetary- and synoptic-scale influences on Eastern Pacific tropical cyclogenesis. Mon. Wea. Rev., 128, 3296-3307. , D. Knight, M. Dickinson, D. Vollaro, and S. Skubis, 1997: Potential vorticity, easterly waves, and Eastern Pacific tropical cyclogenesis. Mon. Wea. Rev., 125, 2699-2708.

Montgomery, M. T., M. E. Nicholls, T. A. Cram, and A. B. Saunders, 2006: A vortical hot tower route to tropical cyclogenesis. J. Atmos. Sci., 63, 355-386.

Mozer, J. B., and J. A. Zehnder, 1996: Lee vorticity production by large-scale tropical mountain ranges. Part I: Eastern North Pacific tropical cyclogenesis. J. Atmos. Sci., 53, 521-538. 
699 National Hurricane Center, cited 2011: NHC archive of hurricane seasons. [Available online at $700 \quad$ http://www.nhc.noaa.gov/pastall.shtml.]

701 Nolan, D. S., 2007: What is the trigger for tropical cyclogenesis? Aust. Meteorol. Mag., 56, 241$702 \quad 266$.

703 Norquist, D. C., E. E. Recker, and R. J. Reed, 1977: The energetics of wave disturbances as 704 observed during phase III of GATE. Mon. Wea. Rev., 105, 334-342.

705 Panofsky, H. A., and G. W. Brier, 1958: Some applications of statistics to meteorology. The 706 Pennsylvania State University, 224 pp.

707 Petersen, W. A., R. Cifelli, D. J. Boccippio, S. A. Rutledge, and C. Fairall, 2003: Convection and 708 easterly wave structures observed in the eastern Pacific warm pool during EPIC-2001. J. $709 \quad$ Atmos. Sci., 60, 1754-1773.

710 _ and D. J. Boccippio, 2004: Variability of convective structure and lightning activity in 711 tropical easterly waves. Preprints, $26^{\text {th }}$ Conf. on Hurricanes and Tropical Meteorology, 712 Miami Beach, FL, Amer. Meteor. Soc.

713 Price, C., Y. Yair, and M. Asfur, 2007: East African lightning as a precursor of Atlantic 714 hurricane activity. Geophys. Res. Lett., 34, L09805, doi:10.1029/2006GL028884.

715 Raymond, D. J., S. L. Sessions, and C. Lopez Carrillo, 2011: Thermodynamics of tropical 716 cyclogenesis in the northwest Pacific. J. Geophys. Res., 116, D18101, 717 doi:10.1029/2011JD015624.

718 Reasor, P. D., M. T. Montgomery, and L. F. Bosart, 2005: Mesoscale observations of the genesis 719 of Hurricane Dolly (1996). J. Atmos. Sci., 62, 3151-3171. 
720 Reed, R. J., D. C. Norquist, and E. E. Recker, 1977: The structure and properties of African 721 wave disturbances as observed during phase III of GATE. Mon. Wea. Rev., 105, 317$722 \quad 333$.

723 Ritchie, E. A., and G. J. Holland, 1997: Scale interactions during the formation of Typhoon 724 Irving. Mon. Wea. Rev., 125, 1377-1396.

725 Rotunno, R., and K. A. Emanuel, 1987: An air-sea interaction theory for tropical cyclones. Part 726 II: Evolutionary study using a non-hydrostatic axisymmetric numerical model. J. Atmos. 727 Sci., 44, 542-561.

728 Rutledge, S. A., E. R. Williams, and T. D. Keenan, 1992: The down under Doppler and 729 electricity experiment (DUNDEE): Overview and preliminary results. Bull. Amer. $730 \quad$ Meteor. Soc., 73, 3-16.

731 Saunders, C. P. R., and S. L. Peck, 1998: Laboratory studies of the influence of the rime accretion rate on charge transfer during crystal/graupel collisions. J. Geophys. Res., 103, 13949-13956.

734 Serra, Y. L., G. N. Kiladis, and M. F. Cronin, 2008: Horizontal and vertical structure of easterly waves in the Pacific ITCZ. J. Atmos. Sci., 65, 1266-1284. , and K. I. Hodges, 2010: Tracking and mean structure of easterly waves over the Intra-Americas Sea. J. Climate, 23, 4823-4840.

738 Sippel, J. A., J. W. Nielsen-Gammon, and S. E. Allen, 2006: The multiple-vortex nature of tropical cyclogenesis. Mon. Wea. Rev., 134, 1796-1814.

740 Smith, E. A., H. J. Cooper, X. Xiang, A. Mugnai, and G. J. Tripoli, 1992: Foundations for 741 statistical-physical precipitation retrieval from passive microwave satellite measurements. 
Part I: Brightness temperature properties of a time-dependent cloud-radiation model. $J$. Appl. Meteor., 31, 506-531.

744 Spencer, R. W., H. M. Goodman, and R. E. Hood, 1989: Precipitation retrieval over land and ocean with the SSM/I: Identification and characteristics of the scattering signal. J. Atmos.

Takahashi, T., 1978: Riming electrification as a charge generation mechanism in thunderstorms. J. Atmos. Sci., 35, 1536-1548.

Thompson, R. M., S. W. Payne, E. E. Recker, and R. J. Reed, 1979: Structure and properties of synoptic-scale wave disturbances in the intertropical convergence zone of the eastern Atlantic. J. Atmos. Sci., 36, 53-72.

Thorncroft, C. D., N. M. J. Hall, and G. N. Kiladis, 2008: Three-dimensional structure and dynamics of African easterly waves. Part III: Genesis. J. Atmos. Sci., 65, 3596-3607.

Toracinta, E. R., D. J. Cecil, E. J. Zipser, and S. W. Nesbitt, 2002: Radar, passive microwave, and lightning characteristics of precipitating systems in the tropics. Mon. Wea. Rev., 130,

Zehnder, J. A., 1991: The interaction of planetary-scale tropical easterly waves with topography: A mechanism for the initiation of tropical cyclones. J. Atmos. Sci., 448, 1217-1230. 

, D. M. Powell, and D. L. Ropp, 1999: The interaction of easterly waves, orography, and the intertropical convergence zone in the genesis of eastern Pacific tropical cyclones. Mon. Wea. Rev., 127, 1566-1585.

768 Zipser, E. J., 1994: Deep cumulonimbus cloud systems in the tropics with and without lightning.

769 Mon. Wea. Rev., 122, 1837-1851.

770

771

772

773

774

775

776

777

778

779

780

781

782

783

784

785

786

787 


\section{List of Figures}

1 Map showing the location of the full analysis domain $\left(130^{\circ} \mathrm{W}-20^{\circ} \mathrm{E}\right)$ and smaller

296 Precipitation Radar (PR) convective reflectivity (only values classified as convective are used) differences between East Atlantic developing waves (EADWs) and nondeveloping longitude bands utilized for this study. EPC represents the East Pacific band, CAR the Caribbean and Central America band, WAT the West Atlantic band, EAT the East Atlantic band, and AFR the Africa longitude band 37

.
waves (NDWs; i.e., EADW minus NDW values) as a function of height and wave phase valid over the East Atlantic. The dashed horizontal lines depict the value of the standard deviation at each height, and the squares indicate EADW values that are significantly greater than the corresponding values of NDWs valid at the $99 \%$ level..... 38

3 Precipitation Radar convective reflectivity (only values classified as convective are used)

8094 Precipitation Radar (PR) convective reflectivity (only values classified as convective are 810 used) differences between East Pacific developing waves (EPDWs) and nondeveloping 811 waves (NDWs; i.e., EPDW minus NDW values) as a function of height and wave phase 812 valid over the East Pacific valid for July-August only. The dashed horizontal lines 
813 depict the value of half the standard deviation at each height, and the squares indicate

814 EPDW values that are significantly greater than the corresponding NDW values valid at

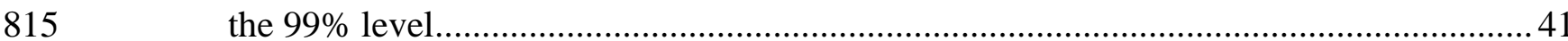

816

817

818

819

820

821

822

823

824

825

826

827

828

829

830

831

832 


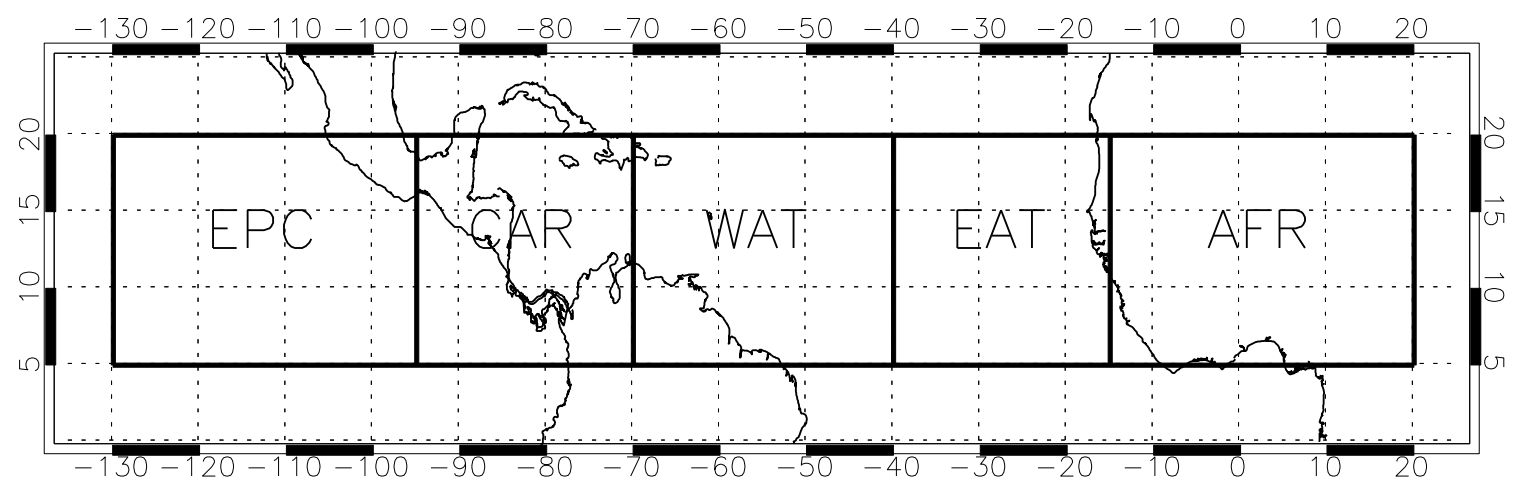

834 FIG. 1. Map showing the location of the full analysis domain $\left(130^{\circ} \mathrm{W}-20^{\circ} \mathrm{E}\right)$ and smaller

835 longitude bands utilized for this study. EPC represents the East Pacific band, CAR the

836 Caribbean and Central America band, WAT the West Atlantic band, EAT the East Atlantic band,

837 and AFR the Africa longitude band.

838

839 


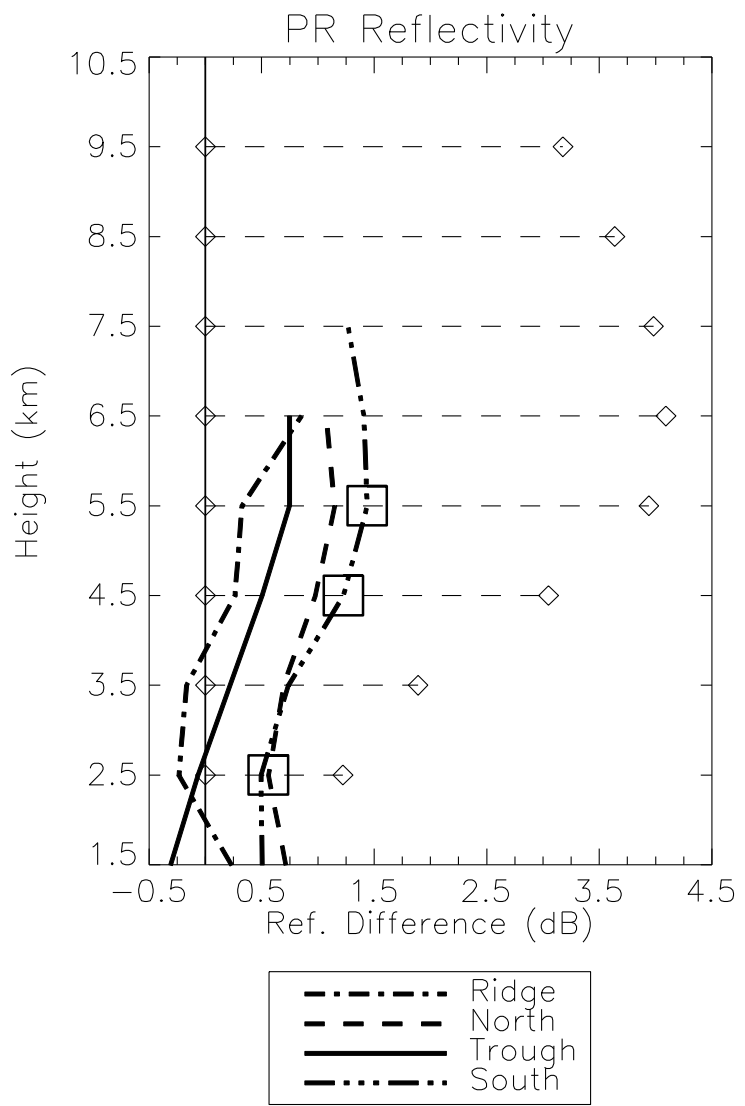

840

841 FIG. 2. Precipitation Radar (PR) convective reflectivity (only values classified as convective are

842 used) differences between East Atlantic developing waves (EADWs) and nondeveloping waves

843 (NDWs; i.e., EADW minus NDW values) as a function of height and wave phase valid over the

844 East Atlantic. The dashed horizontal lines depict the value of half the standard deviation at each

845 height, and the squares indicate EADW values that are significantly greater than the

846 corresponding values of NDWs valid at the $99 \%$ level. 

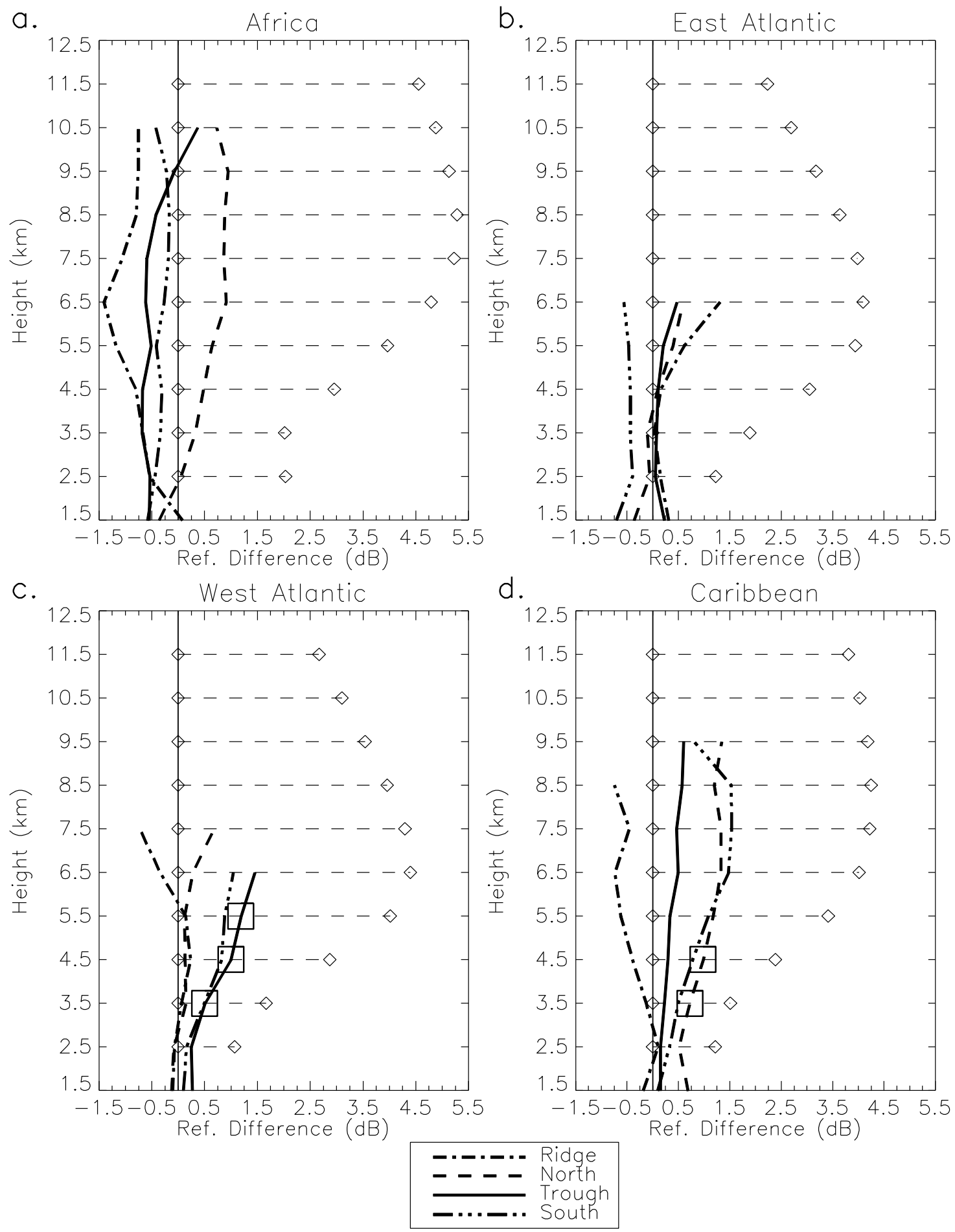

847

848 FIG. 3. Precipitation Radar convective reflectivity (only values classified as convective are used)

849 differences between West Atlantic - Caribbean developing waves (WACDWs) and 
850 nondeveloping waves (NDWs; i.e., WACDW minus NDW values) as a function of height and

851 wave phase valid over a.) Africa b.) the East Atlantic c.) the West Atlantic, and d.) the

852 Caribbean. The dashed horizontal lines depict the value of half the standard deviation at each

853 height, and the squares indicate WACDW values that are significantly greater than the

854 corresponding NDW values valid at the 99\% level.

855

856

857

858

859

860

861 


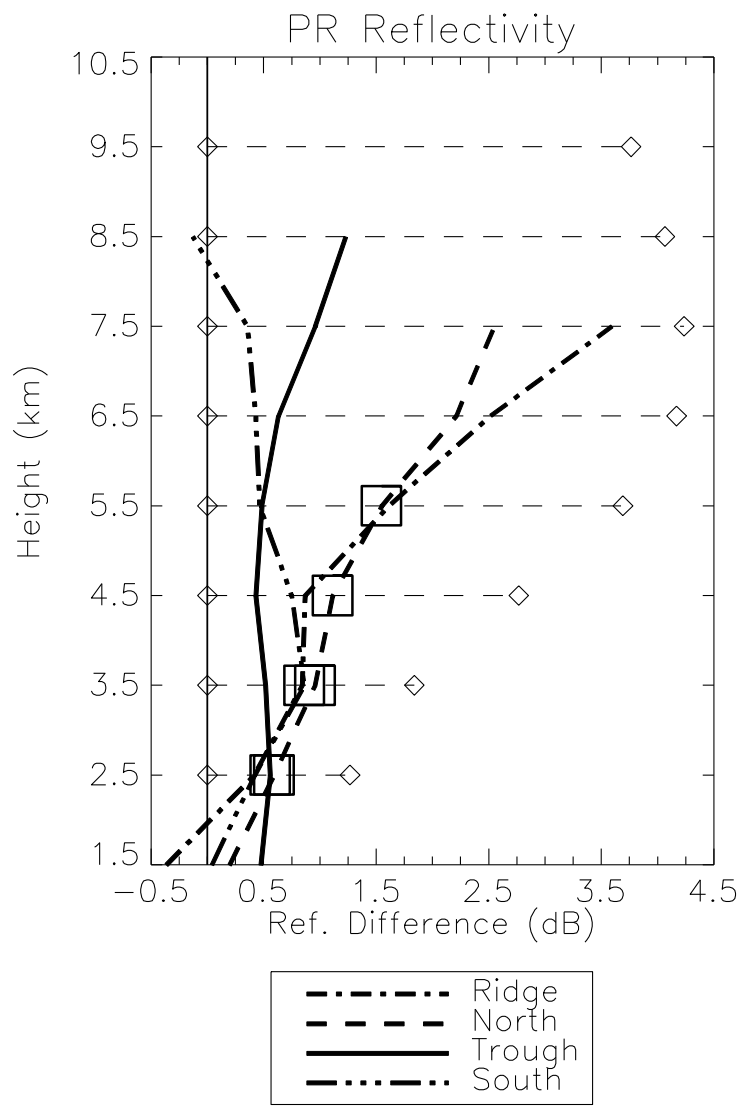

862

863 FIG. 4. Precipitation Radar (PR) convective reflectivity (only values classified as convective are 864 used) differences between East Pacific developing waves (EPDWs) and nondeveloping waves 865 (NDWs; i.e., EPDW minus NDW values) as a function of height and wave phase valid over the 866 East Pacific valid for July-August only. The dashed horizontal lines depict the value of half the 867 standard deviation at each height, and the squares indicate EPDW values that are significantly 868 greater than the corresponding NDW values valid at the $99 \%$ level. 


\section{List of Tables}

877

8801 Definitions and acronyms associated with various wave categories used in this study ... 45

8812 The number of distinct easterly waves and data points used for the trough composites of nondeveloping waves (NDWs), East Atlantic developing waves (EADWs), West Atlantic - Caribbean developing waves (WACDWs), and East Pacific developing waves (EPDWs). The numbers of distinct waves are valid over the full analysis domain (ALL) while the trough points are valid over individual longitude bands (bands defined as in Fig. 1). The asterisk indicates wave categories that are valid for July-August only. The number of individual NDWs is an estimate and includes an estimate of uncertainty because of the difficulty in counting these waves (see text). Finally, the missing values

8903 The fractional coverage by IR brightness temperatures $\leq 240 \mathrm{~K}$ and $\leq 210 \mathrm{~K}$ for East Atlantic developing wave (EADW), West Atlantic - Caribbean developing wave (WACDW), and nondeveloping wave (NDW) phases valid over various longitude bands. The bold (italic) numbers indicate values that are significantly greater (less) than the

8954 Percentage convective coverage as a function of wave phase for East Atlantic developing waves (EADWs), West Atlantic - Caribbean developing waves (WACDWs), and nondeveloping waves (NDWs) valid over various longitude bands. The bold and italic 
9006 Mean polarization corrected temperatures at 37.0 and $85.5 \mathrm{GHz}$ using $37.0-\mathrm{GHz}$ values $901 \leq 260 \mathrm{~K}$ and $85.5-\mathrm{GHz}$ values $\leq 200 \mathrm{~K}$ (i.e., values associated with deep convection) for 902 East Atlantic developing wave (EADW), West Atlantic - Caribbean developing wave 903 (WACDW), and nondeveloping wave (NDW) phases valid over various longitude bands. 904 No EADW or WACDW values are significantly different from those of NDWs valid at

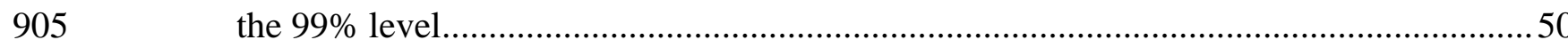

9067 The fractional coverage by IR brightness temperatures $\leq 240 \mathrm{~K}$ and $\leq 210 \mathrm{~K}$, mean 907 polarization corrected temperatures $(\mathrm{K})$ at 37.0 and $85.5 \mathrm{GHz}$ using the same thresholds 908 as in Table 6, convective coverage (\%), and lightning flash rates (flashes day ${ }^{-1}$ ) for 909 developing and nondeveloping waves (30-50\% Dev. and 30-50\% ND, respectively) that 910 were assigned a $30-50 \%$ probability of development within the next 48 hours by the 911 National Hurricane Center. Note that none of the 30-50\% Dev. values are significantly 912 different from the corresponding 30-50\% ND values valid at the $99 \%$ level ................51

9138 The factional coverage by IR brightness temperatures $\leq 240 \mathrm{~K}$ and $\leq 210 \mathrm{~K}$ for East 914 Pacific developing wave (EPDW) and nondeveloping wave (NDW) phases valid over 915 various longitude bands using only data valid for July and August. The bold and italic $916 \quad$ values are as in Table 3

9179 Lightning flash rates (flashes day ${ }^{-1}$ ) for East Pacific developing wave (EPDW) and 918 nondeveloping wave (NDW) phases valid over various longitude bands using only data 919 valid for July and August. The bold and italic values are as in Table 3 53

$920 \quad 10$ A summary of the convective parameters that provide the greatest distinction between 921 nondeveloping waves and East Atlantic developing waves (EADWs), West Atlantic 922 Caribbean developing waves (WACDWs), and East Pacific developing waves (EPDWs) 
over various regions $($ EAT $=$ East Atlantic, WAT $=$ West Atlantic, CAR $=$ Caribbean, and

924 EPC $=$ East Pacific) in various phases. Suggested thresholds to initially be tested to

925 determine the utility of these parameters for tropical cyclogenesis forecasting are also

926 provided. Note that the $240 \mathrm{~K}$ and $210 \mathrm{~K}$ IR coverage thresholds are nondimensional, 
947 TABLE 1. Definitions and acronyms associated with various wave categories used in this study.

\begin{tabular}{|c|c|c|}
\hline Wave Category & Acronym & Definition \\
\hline $\begin{array}{c}\text { East Atlantic developing } \\
\text { wave }\end{array}$ & EADW & $\begin{array}{c}\text { Wave developed a tropical depression over the East } \\
\text { Atlantic longitude band }\end{array}$ \\
\hline $\begin{array}{c}\text { West Atlantic - Caribbean } \\
\text { developing wave }\end{array}$ & WACDW & $\begin{array}{c}\text { Wave developed a tropical depression over the } \\
\text { West Atlantic or Caribbean longitude band }\end{array}$ \\
\hline $\begin{array}{c}\text { East Pacific developing } \\
\text { wave }\end{array}$ & EPDW & $\begin{array}{c}\text { Wave developed a tropical depression over the East } \\
\text { Pacific longitude band }\end{array}$ \\
\hline Nondeveloping wave & NDW & $\begin{array}{c}\text { Wave never developed a tropical cyclone of at least } \\
\text { tropical storm strength }\end{array}$ \\
\hline
\end{tabular}

948

949

950

951

952

953

954

955

956

957

958

959

960

961

962

963

964 
965 TABLE 2 . The number of distinct easterly waves and data points used for the trough composites 966 of nondeveloping waves (NDWs), East Atlantic developing waves (EADWs), West Atlantic -

967 Caribbean developing waves (WACDWs), and East Pacific developing waves (EPDWs). The

968 numbers of distinct waves are valid over the full analysis domain (ALL) while the trough points

969 are valid over individual longitude bands (bands defined as in Fig. 1). The asterisk indicates

970 wave categories that are valid for July-August only. The number of individual NDWs is an

971 estimate and includes an estimate of uncertainty because of the difficulty in counting these waves

972 (see text). Finally, the missing values are for those composites that were unavailable.

973

\begin{tabular}{rcccccc}
\multicolumn{3}{c}{ Distinct AEWs } & \multicolumn{5}{c}{ Trough Points } \\
NDW & ALL & EPC & CAR & WAT & EAT & AFR \\
EADW & 28 & 2582 & 1695 & 1978 & 1737 & 2505 \\
WACDW & 37 & - & - & - & 138 & 313 \\
EPDW $^{*}$ & 68 & 267 & 358 & 361 & 287 & 392 \\
NDW $^{*}$ & $100 \pm 15$ & 612 & 449 & 467 & 454 & 573
\end{tabular}

974

975

976

977

978

979

980

981

982

983

984 
985 TABLE 3 . The fractional coverage by IR brightness temperatures $\leq 240 \mathrm{~K}$ and $\leq 210 \mathrm{~K}$ for East

986 Atlantic developing wave (EADW), West Atlantic - Caribbean developing wave (WACDW),

987 and nondeveloping wave (NDW) phases valid over various longitude bands. The bold (italic)

988 numbers indicate values that are significantly greater (less) than the corresponding NDW values

989 valid at the $99 \%$ level.

IR Brightness Temperature Thresholds

Africa

\begin{tabular}{rcccccccc}
\multicolumn{9}{c}{$240 K$} \\
& Ridge & Northerly & Trough & Southerly & Ridge & Northerly & Trough & Southerly \\
EADW & $\mathbf{0 . 0 9 7}$ & $\mathbf{0 . 1 1 1}$ & $\mathbf{0 . 0 8 8}$ & $\mathbf{0 . 0 8 2}$ & $\mathbf{0 . 0 1 7}$ & $\mathbf{0 . 0 2 1}$ & 0.015 & $\mathbf{0 . 0 1 4}$ \\
WACDW & 0.068 & $\mathbf{0 . 0 8 5}$ & $\mathbf{0 . 0 8 3}$ & $\mathbf{0 . 0 7 9}$ & 0.013 & $\mathbf{0 . 0 1 7}$ & $\mathbf{0 . 0 1 5}$ & $\mathbf{0 . 0 1 3}$ \\
NDW & 0.061 & 0.073 & 0.071 & 0.065 & 0.010 & 0.014 & 0.013 & 0.010
\end{tabular}

East Atlantic

\begin{tabular}{rcccccccc}
\multicolumn{9}{c}{$240 K$} \\
& Ridge & Northerly & Trough & Southerly & Ridge & Northerly & Trough & Southerly \\
EADW & 0.064 & $\mathbf{0 . 0 9 4}$ & $\mathbf{0 . 0 9 4}$ & 0.085 & 0.006 & $\mathbf{0 . 0 0 9}$ & $\mathbf{0 . 0 1 0}$ & 0.009 \\
WACDW & 0.046 & 0.064 & $\mathbf{0 . 0 8 6}$ & 0.069 & 0.004 & 0.004 & $\mathbf{0 . 0 0 8}$ & 0.005 \\
NDW & 0.072 & 0.059 & 0.075 & 0.088 & 0.005 & 0.004 & 0.006 & 0.007
\end{tabular}

West Atlantic

\section{$240 \mathrm{~K} \quad 210 \mathrm{~K}$}

$\begin{array}{rcccccccc} & \text { Ridge } & \text { Northerly } & \text { Trough } & \text { Southerly } & \text { Ridge } & \text { Northerly } & \text { Trough } & \text { Southerly } \\ \text { WACDW } & 0.077 & \mathbf{0 . 0 6 7} & \mathbf{0 . 1 0 3} & \mathbf{0 . 1 1 0} & 0.007 & \mathbf{0 . 0 0 8} & \mathbf{0 . 0 1 1} & \mathbf{0 . 0 1 5} \\ \text { NDW } & 0.062 & 0.045 & 0.056 & 0.068 & 0.005 & 0.004 & 0.005 & 0.006\end{array}$

\section{Caribbean}

$240 K$

Ridge Northerly Trough Southerly

WACDW 0.148

NDW 0.116

0.162

0.119

0.169

0.130

0.163

0.131
$210 \mathrm{~K}$

Ridge Northerly Trough Southerly

$\begin{array}{llll}0.025 & \mathbf{0 . 0 2 9} & \mathbf{0 . 0 3 2} & 0.029\end{array}$

$\begin{array}{llll}0.017 & 0.019 & 0.022 & 0.022\end{array}$

991

992

993

994

995 
996 TABLE 4. Percentage convective coverage as a function of wave phase for East Atlantic

997 developing waves (EADWs), West Atlantic - Caribbean developing waves (WACDWs), and

998 nondeveloping waves (NDWs) valid over various longitude bands. The bold and italic values

999 are as in Table 3.

\begin{tabular}{rcccc}
\multicolumn{5}{c}{ Convective Coverage (\%) } \\
Africa \\
EADW & Ridge & Northerly & Trough & Southerly \\
WACDW & 1.11 & 1.16 & 0.96 & 0.91 \\
NDW & 0.74 & 0.91 & 0.86 & 0.89 \\
\multicolumn{5}{c}{ East Atlantic } \\
E.78 & 0.76 & 0.80 & 0.78 \\
EADW & Ridge & Northerly & Trough & Southerly \\
WACDW & 1.18 & 1.48 & 1.41 & 1.18 \\
NDW & 1.02 & 1.07 & 1.24 & 1.10 \\
& \multicolumn{5}{c}{ West Atlantic } & 1.16 & 1.11 \\
WACDW & 1.44 & 1.42 & 1.70 & 1.59 \\
NDW & 1.25 & 1.33 & 1.43 & 1.46 \\
& \multicolumn{5}{c}{ Caribbean } \\
& Ridge & Northerly & Trough & Southerly \\
WACDW & 1.77 & 2.03 & 1.76 & 1.81 \\
NDW & 1.70 & 1.66 & 1.78 & 1.73
\end{tabular}

1001

1002

1003

1004

1005

1006

1007

1008

1009 
1010 TABLE 5. As in Table 4, except for lightning flash rates (flashes day ${ }^{-1}$ ).

\section{Lightning Flash Rates}

\section{Africa}

\begin{tabular}{|c|c|c|c|c|}
\hline & Ridge & Northerly & Trough & Southerly \\
\hline EADW & 179.2 & 133.2 & 109.0 & 153.8 \\
\hline WACDW & 139.6 & 128.7 & 115.1 & 127.4 \\
\hline NDW & 110.7 & 103.0 & 107.1 & 109.7 \\
\hline \multicolumn{5}{|c|}{ East Atlantic } \\
\hline & Ridge & Northerly & Trough & Southerly \\
\hline EADW & 3.5 & 4.6 & 6.0 & 7.6 \\
\hline ACDW & 1.0 & 3.3 & 5.0 & 6.1 \\
\hline NDW & 2.4 & 3.0 & 4.4 & 8.5 \\
\hline \multicolumn{5}{|c|}{ West Atlantic } \\
\hline & Ridge & Northerly & Trough & Southerly \\
\hline ACDW & 10.8 & 26.8 & 23.6 & 17.8 \\
\hline NDW & 23.1 & 24.6 & 17.0 & 14.5 \\
\hline \multicolumn{5}{|c|}{ Caribbean } \\
\hline & Ridge & Northerly & Trough & Southerly \\
\hline ACDW & 96.8 & 135.6 & 115.7 & 130.4 \\
\hline NDW & 83.9 & 94.6 & 104.6 & 107.2 \\
\hline
\end{tabular}

1011

1012

1013

1014

1015

1016

1017

1018

1019

1020

1021

1022 
1023 TABLE 6. Mean polarization corrected temperatures at 37.0 and $85.5 \mathrm{GHz}$ using $37.0-\mathrm{GHz}$

1024 values $\leq 260 \mathrm{~K}$ and $85.5-\mathrm{GHz}$ values $\leq 200 \mathrm{~K}$ (i.e., values associated with deep convection) for

1025 East Atlantic developing wave (EADW), West Atlantic - Caribbean developing wave

1026 (WACDW), and nondeveloping wave (NDW) phases valid over various longitude bands. No

1027 EADW or WACDW values are significantly different from those of NDWs valid at the $99 \%$

1028 level.

\section{Polarization Corrected Temperatures}

Africa

\begin{tabular}{rcccccccc} 
& \multicolumn{9}{c}{37.0} & \multicolumn{5}{c}{85.5} \\
EADW & 250.3 & 251.0 & 251.2 & 251.9 & 174.9 & 175.8 & 177.0 & 177.1 \\
WACDW & 251.5 & 252.2 & 251.6 & 251.6 & 175.1 & 176.0 & 176.3 & 176.1 \\
NDW & 251.4 & 251.7 & 251.7 & 251.7 & 176.4 & 176.4 & 177.0 & 177.7
\end{tabular}

\section{East Atlantic}

$37.0 \quad 85.5$

$\begin{array}{rcccccccc} & \text { Ridge } & \text { Northerly } & \text { Trough } & \text { Southerly } & \text { Ridge } & \text { Northerly } & \text { Trough } & \text { Southerly } \\ \text { EADW } & 257.4 & 256.4 & 256.5 & 256.1 & 185.9 & 184.0 & 184.3 & 183.0 \\ \text { WACDW } & 254.4 & 256.8 & 256.6 & 256.4 & 185.9 & 184.3 & 185.0 & 185.3 \\ \text { NDW } & 257.0 & 257.0 & 256.7 & 256.2 & 186.3 & 185.3 & 185.6 & 185.3\end{array}$

West Atlantic

$37.0 \quad 85.5$

\begin{tabular}{rcccccccc} 
& Ridge & Northerly & Trough & Southerly & Ridge & Northerly & Trough & Southerly \\
WACDW & 255.8 & 254.5 & 255.2 & 255.5 & 183.7 & 181.5 & 183.5 & 182.2 \\
NDW & 255.3 & 254.7 & 255.3 & 255.6 & 183.0 & 182.0 & 183.1 & 183.4 \\
& \multicolumn{8}{c}{ Caribbean }
\end{tabular}

37.0

\section{5}

$\begin{array}{rcccccccc} & \text { Ridge } & \text { Northerly } & \text { Trough } & \text { Southerly } & \text { Ridge } & \text { Northerly } & \text { Trough } & \text { Southerly } \\ \text { WACDW } & 255.5 & 252.6 & 253.2 & 253.3 & 181.0 & 177.5 & 177.4 & 178.4 \\ \text { NDW } & 253.7 & 253.5 & 253.3 & 253.2 & 178.0 & 178.6 & 178.6 & 178.5\end{array}$

1030

1031

1032

1033

1034 
1035 TABLE 7 . The fractional coverage by IR brightness temperatures $\leq 240 \mathrm{~K}$ and $\leq 210 \mathrm{~K}$, mean 1036 polarization corrected temperatures $(\mathrm{K})$ at 37.0 and $85.5 \mathrm{GHz}$ using the same thresholds as in

1037 Table 6, convective coverage (\%), and lightning flash rates (flashes day ${ }^{-1}$ ) for developing and

1038 nondeveloping waves (30-50\% Dev. and 30-50\% ND, respectively) that were assigned a

$103930-50 \%$ probability of development within the next 48 hours by the National Hurricane Center.

1040 Note that none of the 30-50\% Dev. values are significantly different from the corresponding 30-

$104150 \%$ ND values valid at the $99 \%$ level.

\begin{tabular}{|c|c|c|c|c|c|}
\hline & \multicolumn{5}{|c|}{ IR Brightness Temperature Thresholds } \\
\hline & & Ridge & Northerly & Trough & Southerly \\
\hline \multirow[t]{2}{*}{$30-50 \%$ Dev. } & $240 \mathrm{~K}$ & 0.108 & 0.115 & 0.154 & 0.172 \\
\hline & $210 \mathrm{~K}$ & 0.011 & 0.014 & 0.021 & 0.024 \\
\hline \multirow{4}{*}{$30-50 \%$ ND } & $240 \mathrm{~K}$ & 0.104 & 0.079 & 0.133 & 0.125 \\
\hline & $210 \mathrm{~K}$ & 0.015 & 0.009 & 0.021 & 0.021 \\
\hline & \multicolumn{5}{|c|}{ Polarization Corrected Temperatures } \\
\hline & & Ridge & Northerly & Trough & Southerly \\
\hline \multirow[t]{2}{*}{$30-50 \%$ Dev. } & 37.0 & 254.7 & 254.7 & 255.0 & 255.4 \\
\hline & 85.5 & 185.4 & 182.1 & 182.2 & 183.0 \\
\hline \multirow[t]{2}{*}{$30-50 \%$ ND } & 37.0 & 255.7 & 256.7 & 256.1 & 255.0 \\
\hline & 85.5 & 180.1 & 183.1 & 183.6 & 180.6 \\
\hline
\end{tabular}

\begin{tabular}{rcccc} 
& \multicolumn{4}{c}{ Convective Coverage } \\
& Ridge & Northerly & Trough & Southerly \\
$\mathbf{3 0 - 5 0 \% ~ D e v . ~}$ & 1.56 & 1.48 & 1.93 & 1.93 \\
$\mathbf{3 0 - 5 0} \%$ ND & 1.62 & 1.20 & 1.38 & 1.69
\end{tabular}

$\begin{array}{cccc}\text { Ridge } & \text { Northerly } & \text { Trough } & \text { Southerly } \\ 93.2 & 40.4 & 58.0 & 43.5 \\ 38.3 & 8.2 & 10.5 & 89.1\end{array}$


1046 TABLE 8. The factional coverage by IR brightness temperatures $\leq 240 \mathrm{~K}$ and $\leq 210 \mathrm{~K}$ for East

1047 Pacific developing wave (EPDW) and nondeveloping wave (NDW) phases valid over various

1048 longitude bands using only data valid for July and August. The bold and italic values are as in

1049 Table 3.

IR Brightness Temperature Thresholds (July-August Only)

Africa

\begin{tabular}{rcccccccc} 
& \multicolumn{9}{c}{$240 K$} & \multicolumn{4}{c}{$210 K$} \\
EPDW & Ridge & Northerly & Trough & Southerly & Ridge & Northerly & Trough & Southerly \\
NDW & 0.083 & 0.100 & 0.093 & 0.068 & 0.014 & 0.017 & 0.016 & 0.011 \\
& 0.089 & 0.116 & 0.105 & 0.081 & 0.017 & 0.023 & 0.019 & 0.013
\end{tabular}

East Atlantic

\begin{tabular}{ccccccccc}
\multicolumn{9}{c}{$240 K$} \\
& Ridge & Northerly & Trough & Southerly & Ridge & Northerly & Trough & Southerly \\
EPDW & 0.054 & 0.048 & 0.057 & 0.049 & 0.004 & 0.003 & 0.004 & 0.002 \\
NDW & 0.048 & 0.052 & 0.064 & 0.053 & 0.003 & 0.003 & 0.005 & 0.004
\end{tabular}

West Atlantic

\begin{tabular}{rcccccccc} 
& \multicolumn{9}{c}{$240 K$} & \multicolumn{5}{c}{$210 K$} \\
EPDW & Ridge & Northerly & Trough & Southerly & Ridge & Northerly & Trough & Southerly \\
NDW & 0.051 & 0.041 & 0.054 & 0.058 & 0.004 & 0.003 & 0.004 & 0.005 \\
& 0.037 & 0.042 & 0.047 & 0.050 & 0.003 & 0.003 & 0.004 & 0.004
\end{tabular}

Caribbean

\begin{tabular}{|c|c|c|c|c|c|c|c|c|}
\hline & \multicolumn{4}{|c|}{$240 \mathrm{~K}$} & \multicolumn{4}{|c|}{$210 \mathrm{~K}$} \\
\hline & Ridge & Northerly & Trough & Southerly & Ridge & Northerly & Trough & Southerly \\
\hline EPDW & 0.141 & 0.151 & 0.156 & 0.166 & 0.022 & 0.026 & 0.027 & 0.029 \\
\hline NDW & 0.124 & 0.146 & 0.149 & 0.136 & 0.020 & 0.026 & 0.027 & 0.023 \\
\hline \multicolumn{9}{|c|}{ East Pacific } \\
\hline & \multicolumn{4}{|c|}{$240 \mathrm{~K}$} & \multicolumn{4}{|c|}{$210 \mathrm{~K}$} \\
\hline & Ridge & Northerly & Trough & Southerly & Ridge & Northerly & Trough & Southerly \\
\hline EPDW & 0.099 & 0.130 & 0.154 & 0.180 & 0.010 & 0.016 & 0.022 & 0.024 \\
\hline NDW & 0.073 & 0.084 & 0.116 & 0.122 & 0.006 & 0.008 & 0.013 & 0.014 \\
\hline
\end{tabular}

1051

1052

1053

1054

1055 
1056 TABLE 9. Lightning flash rates (flashes day ${ }^{-1}$ ) for East Pacific developing wave (EPDW) and 1057 nondeveloping wave (NDW) phases valid over various longitude bands using only data valid for 1058 July and August. The bold and italic values are as in Table 3.

1059

\begin{tabular}{|c|c|c|c|c|}
\hline \multicolumn{5}{|c|}{ Lightning Flash Rates (July-August Only) } \\
\hline \multicolumn{5}{|c|}{ Africa } \\
\hline & Ridge & Northerly & Trough & Southerly \\
\hline EPDW & 123.6 & 131.6 & 138.4 & 109.6 \\
\hline NDW & 206.7 & 143.8 & 142.4 & 120.8 \\
\hline \multicolumn{5}{|c|}{ East Atlantic } \\
\hline & Ridge & Northerly & Trough & Southerly \\
\hline EPDW & 2.8 & 1.4 & 3.1 & 3.7 \\
\hline NDW & 1.2 & 0.6 & 3.0 & 3.5 \\
\hline \multicolumn{5}{|c|}{ West Atlantic } \\
\hline & Ridge & Northerly & Trough & Southerly \\
\hline EPDW & 12.1 & 14.2 & 19.8 & 16.2 \\
\hline NDW & 8.2 & 16.6 & 14.8 & 17.4 \\
\hline \multicolumn{5}{|c|}{ Caribbean } \\
\hline & Ridge & Northerly & Trough & Southerly \\
\hline EPDW & 104.8 & 138.3 & 137.4 & 115.5 \\
\hline NDW & 112.0 & 161.1 & 126.1 & 119.6 \\
\hline \multicolumn{5}{|c|}{ East Pacific } \\
\hline & Ridge & Northerly & Trough & Southerly \\
\hline EPDW & 58.5 & 68.2 & 72.8 & 69.5 \\
\hline NDW & 18.9 & 32.2 & 37.0 & 36.4 \\
\hline
\end{tabular}

1060

1061

1062

1063

1064

1065

1066

1067

1068 
1069 TABLE 10. A summary of the convective parameters that provide the greatest distinction

1070 between nondeveloping waves and East Atlantic developing waves (EADWs), West Atlantic -

1071 Caribbean developing waves (WACDWs), and East Pacific developing waves (EPDWs) over

1072 various regions $(\mathrm{EAT}=$ East Atlantic, $\mathrm{WAT}=$ West Atlantic, $\mathrm{CAR}=$ Caribbean, and $\mathrm{EPC}=\mathrm{East}$

1073 Pacific) in various phases. Suggested thresholds to initially be tested to determine the utility of

1074 these parameters for tropical cyclogenesis forecasting are also provided. Note that the $240 \mathrm{~K}$ and

$1075210 \mathrm{~K}$ IR coverage thresholds are nondimensional, while the flash rate threshold has units of

1076 flashes day ${ }^{-1}$.

Convective Parameters and Thresholds

\begin{tabular}{|c|c|c|c|c|}
\hline Wave Type & Location & Phase & Parameter & Threshold \\
\hline EADW & EAT & $\begin{array}{c}\text { northerly/ } \\
\text { trough }\end{array}$ & $\begin{array}{l}240 \mathrm{~K} \mathrm{IR} \\
\text { coverage }\end{array}$ & 0.090 \\
\hline EADW & EAT & $\begin{array}{c}\text { northerly/ } \\
\text { trough }\end{array}$ & $\begin{array}{l}210 \mathrm{~K} \text { IR } \\
\text { coverage }\end{array}$ & 0.009 \\
\hline WACDW & WAT & southerly & $\begin{array}{l}240 \mathrm{~K} \mathrm{IR} \\
\text { coverage }\end{array}$ & 0.085 \\
\hline WACDW & WAT & southerly & $\begin{array}{l}210 \mathrm{~K} \text { IR } \\
\text { coverage }\end{array}$ & 0.009 \\
\hline WACDW & CAR & trough & $\begin{array}{l}240 \mathrm{~K} \mathrm{IR} \\
\text { coverage }\end{array}$ & 0.155 \\
\hline WACDW & CAR & trough & $\begin{array}{l}210 \mathrm{~K} \text { IR } \\
\text { coverage }\end{array}$ & 0.029 \\
\hline EPDW & CAR & southerly & $\begin{array}{l}240 \mathrm{~K} \mathrm{IR} \\
\text { coverage }\end{array}$ & 0.150 \\
\hline EPDW & EPC & $\begin{array}{l}\text { trough/ } \\
\text { southerly }\end{array}$ & $\begin{array}{l}240 \mathrm{~K} \text { IR } \\
\text { coverage }\end{array}$ & 0.140 \\
\hline EPDW & EPC & $\begin{array}{l}\text { northerly/ } \\
\text { trough/ } \\
\text { southerly }\end{array}$ & Flash rate & 60.0 \\
\hline
\end{tabular}

